\title{
Efficiency of Amorphous Calcium Phosphate-Containing Orthodontic Composite and Resin Modified Glass Ionomer on Demineralization Evaluated By a New Laser Fluorescence Device
}

\author{
Tancan Uysala \\ Mihri Amasyalib \\ Alp Erdin Koyuturk \\ Deniz Sagdic ${ }^{b}$
}

\section{ABSTRACT}

Objectives: The aim of this in vitro study was to compare the efficacy of Amorphous Calcium Phosphate (ACP)-containing orthodontic composite and resin-modified glass ionomer cement (RMGIC) on enamel demineralization adjacent to orthodontic brackets evaluated by a new laser fluorescence device.

Methods: Sixty extracted maxillary premolars were used in the present study. Twenty orthodontic brackets were bonded with ACP-containing orthodontic adhesive (Aegis-Ortho), 20 were bonded with RMGIC (Fuji Ortho LC) and 20 were bonded with Transbond XT composite as the control. All samples were then cycled for 21 days through a daily procedure of demineralization for 6 hours and remineralization for 17 hours. After this procedure, demineralization evaluations were undertaken by a pen-type laser fluorescence device (DIAGNO-dent Pen). Analysis of variance (ANOVA) and Tukey test was used for statistical evaluation, at $\mathrm{P}<.05$ level.

Results: According to ANOVA, significant demineralization variations $(\triangle D)$ were determined among groups ( $F=6.650 ; P<.01)$. The ACP-containing composite showed the lowest (mean: $8.98 \pm 2.38$ ) and the control composite showed the highest (mean:12.15 \pm 3.83 ) $\Delta \mathrm{D}$, during 21 days demineralization process $(P<.01)$. Significant difference was also observed between the $\triangle D$ scores of the RMGIC (mean: 9.24 \pm 2.73 ) and control $(P<.05)$. No significant differences was found in preventive effects of ACP-containing composite and RMGIC $(P<.05)$ against demineralization.

Conclusions: The use of both ACP-containing orthodontic composite and RMGIC should be recommended for any at-risk orthodontic patient to provide preventive actions and potentially remineralize subclinical enamel demineralization. (Eur J Dent 2009;3:127-134)

Key words: Demineralization; Amorphous calcium phosphate; Glass ionomer cements.

a Erciyes University, Faculty of Dentistry, Department of Orthodontics, Kayseri, Turkey.

b Gulhane Military Medical Academy, Center of Dental Sciences, Department of Orthodontics, Ankara, Turkey. 19 Mayis University, Faculty of Dentistry, Department of Pediatric Dentistry, Samsun, Turkey.
Corresponding author: Dr. Tancan Uysal Erciyes Universitesi, Dis Hekimligi Fakultesi, Ortodonti Anabilim Dali, Kampus, 38039, Melikgazi, Kayseri, Turkey Phone: +90 352 4374937/29102 Fax: +90 3524380657 E-mail: tancanuysaldyahoo.com 


\section{INTRODUCTION}

One of the most difficult problems in orthodontic treatment with fixed appliances is the control of enamel demineralization around the brackets.' The bands/brackets and the different orthodontic elements that are used lelastics, power chains, sleeves, springs) make the patient's dental hygiene more difficult and the accumulation of plaque easier. ${ }^{2}$ Studies have documented significant increases in oral bacteria during orthodontic treatment. ${ }^{3}$ Previous studies have shown that the rate of demineralization in orthodontic patients was higher than those without orthodontic treatment, ${ }^{4-6}$ and teenagers were at higher risk of demineralization than adults. ${ }^{6}$

The prevalence of demineralization in orthodontic patients has been reported between $2 \%$ and $96 \% .4,7,8$ It has been generally accepted that the combined application of fluoride regimes, oral hygiene instructions, and dietary control can contribute greatly to the inhibition of demineralization during fixed-appliance treatment. 8.9 These methods, however, rely on patient compliance. Other noncompliant methods have been created to deliver fluoride adjacent to orthodontic appliances. ${ }^{10}$

Fluoride varnishes have also been shown to decrease enamel demineralization in vitro and in clinical studies. ${ }^{11-13}$ Fluoride varnish adheres to the enamel surface longer than other topical fluoride products and has been shown to be superior to the use of sodium fluoride and monofluorophosphate toothpastes, weekly acidulated phosphate fluoride gel application and daily sodium fluoride rinses because of its ability to increase fluoride uptake in enamel in vitro. ${ }^{14}$ Overall, the efficacy of regular application of fluoride varnish appears to reduce lesion formation on bracketed maxillary incisor teeth. ${ }^{15}$ Fluoride varnish also provides additional preventive benefits when brackets have been bonded with composite resin cement. ${ }^{16}$ Resinmodified glass ionomer cements (RMGIC) have been developed that combine the desirable properties of composite resin shear bond strength (SBS) and glass ionomer fluoride release. ${ }^{17}$ The RMGICs have been shown to release fluoride and decrease enamel demineralization. 10,17 Several RMGICs have been evaluated for SBS, and two materials were found to have bond strengths comparable to composite resins: Fuji Ortho LC IGC America Inc., Chicago, III.) and Advance (Dentsply/ Caulk, Dentsply International Inc., Milford, Del....18

Demineralization takes place when specific bacteria are retained for a long time on the enamel surface. The bacteria metabolize fermentable carbohydrates and produce organic acids and these acids dissolve the calcium phosphate mineral of the enamel and dentin, resulting in demineralization. ${ }^{19}$ Demineralization is first observed clinically as white spot lesions. The demineralized area beneath the dental plaque and the body of the enamel lesion can lose as much as $50 \%$ of the original mineral content. ${ }^{20}$

In a recent study, Schumacher et a ${ }^{21}$ developed biologically active restorative materials that may stimulate the repair of tooth structure through the release of cavity-fighting components including calcium and phosphate. They contain amorphous calcium phosphate (ACP) as bioactive filler encapsulated in a polymer binder ${ }^{22-24}$ Calcium and phosphate ions released from ACP composites, especially in response to changes in the oral environment caused by bacterial plaque or acidic foods, can be deposited into the tooth structures as an apatite mineral, which is similar to the hydroxyapatite found naturally in teeth. ${ }^{25}$

The ACP has the properties of both a preventive and restorative material that justify its use in dental cements, sealants, composites, ${ }^{21-26,28}$ and, more recently, orthodontic adhesives. ${ }^{27,29,30}$ ACP-filled composite resins have been shown to recover $71 \%$ of the lost mineral content of decalcified teeth. 25 One ACP-containing adhesive, Aegis-Ortho (The Bosworth Co, Skokie, Illinois, USA), has been marketed for using as a light-cured orthodontic adhesive with similar properties to previously used resins. These materials are encouraging to the formation of hydroxyl-apatite, which can be used by the tooth for remineralization. ${ }^{26}$ This important condition can be maintained for a considerable time, offering a promising antagonist to demineralization, and it can promote the prevention of future white spots throughout orthodontic treatment. ${ }^{27}$

Recently, for detecting demineralization areas and caries on occlusal and approximal surfaces of a tooth; a more portable battery powered laser fluorescence device, DIAGNOdent Pen (KaVo) has been marketed. 
Studies have demonstrated the remineralization potential ${ }^{23,25,28}$ in restorative dentistry or SBS of brackets $^{27,29}$ or lingual retainer composites ${ }^{30}$ of ACP-containing materials; but no studies have been performed to investigate the efficiency of ACP-containing orthodontic composite material on enamel demineralization adjacent to orthodontic brackets.

The aim of this in vitro study was to compare the efficacy of ACP-containing orthodontic composite and RMGIC on enamel demineralization adjacent to orthodontic brackets by DIAGNOdent-PEN (KaVo, Biberach, Germany) device, containing a laser-diode as the excitation light source, and a photo-diode combined with a long pass filter, as the detector.

\section{MATERIALS AND METHODS}

Sixty maxillary premolars extracted for orthodontic reasons were stored in distilled water until use (maximum 1-month). Teeth with hypoplastic areas, cracks, or gross irregularities of the enamel structure were excluded from the study. The criteria for tooth selection dictated no pre-treatment with a chemical agent such as alcohol, formalin, hydrogen peroxide, and so forth. Soft tissue remnants and calculus were removed from the teeth, following which they were cleaned with a fluoride-free pumice and rubber cup.

\section{Bonding procedure}

The teeth were distributed into three equal groups: two experimental and one control, each containing 20 teeth. A 37\% ortho-phosphoric acid gel (3M Dental Products, St Paul, Minnesota USA) was used for the acid etching of the teeth for 15 seconds. The teeth were then rinsed with water for 15 seconds and dried with oil-free air for 10 seconds until a frosty white appearance of the etched enamel was observed. After enamel surface preparation, the liquid primer Transbond XT (3M Unitek, Monrovia, California, USAl was applied to the etched surface and not cured according to the manufacturer's recommendation. Transbond XT adhesive was applied to the bracket base, and the bracket was placed onto the tooth in the center of the crown, with the center of the bracket over the long axis of the tooth. The same instructions as in group 1 were followed for the adhesives used in group 2 (Aegis Ortho) and group 3 (Fuji Ortho
LC, GC Company, Tokyo, Japan), except neither required the use of a primer.

Stainless steel orthodontic premolar brackets (Dyna-Lok series, 100-gauge mesh, 3M Unitek) were bonded by standard protocol. A light-emitting diode light unit (Elipar Freelight 2, 3M-ESPE, St. Paul, Minnesota, USA) was used for curing the specimens for 20 seconds.

\section{Demineralization procedure}

Each crown surface of all groups was painted with acid-resistant varnish, leaving an exposed window of enamel (approximately $4.0 \times 2.0 \mathrm{~mm}$ ) on the middle third of the buccal surface, so that most of the crown was covered by acidresistant varnish, and only the exposed enamel would be attacked by acid. The daily procedure of $\mathrm{pH}$ cycling included a demineralization period of 6 hours and a remineralization period of 17 hours. ${ }^{31}$ Each crown was immersed individually in $40 \mathrm{~mL}$ of demineralization solution containing $2.0 \mathrm{mmol} / \mathrm{L}$ calcium, $2.0 \mathrm{mmol} / \mathrm{L}$ phosphate, and $75 \mathrm{mmol} / \mathrm{L}$ acetate at $\mathrm{pH} 4.3$ for 6 hours at $37^{\circ} \mathrm{C}$. Specimens were then removed from the demineralization solution, rinsed with deionized water, and immersed individually in $20 \mathrm{~mL}$ of the remineralization solution at $37^{\circ} \mathrm{C}$ overnight $(17$ hours) to simulate the remineralizing stage of the caries process. ${ }^{31}$ The remineralization solution consisted of $1.5 \mathrm{mmol} / \mathrm{L}$ calcium, $0.9 \mathrm{mmol} / \mathrm{L}$ phosphate, $150 \mathrm{mmol} / \mathrm{L}$ potassium chloride, and $20 \mathrm{mmol} / \mathrm{L}$ cacodylate buffer at $\mathrm{pH}$ 7.0. This cycling system was repeated daily for 21 days.

\section{DIAGNOdent Pen measurements}

Prior to the start of this in vitro study, blind examiner was introduced to the study protocol, the use of the laser fluorescence method and the calibration procedure. The instrument -DIAGNOdent Pen- was calibrated with the own ceramic standard, according to the manufacturer's instructions. The correct calibration was checked after finishing the measurements; no deviations greater than 3 against the ceramic standard occurred during the study period. Examiner was used the same DIAGNOdent Pen with the appropriate measurement tips. The tips were not changed during the procedure and sterilized before the measurement.

The in vitro measurement of each site 
around bracket consisted of a brief air dry for approximately 5 seconds with the air syringe of the dental unit. The inherent fluorescence of each tooth was adjusted by holding the tip against the sound smooth surface of the fissure and pressing the ring button until the calibration was completed. The DIAGNOdent Pen tip was then placed on the measurement site, and slightly tilted circular movements were performed along the entire surface pattern. Examiner was encouraged to remeasure carefully sites with doubtful readings. The maximum reading for each site (mesial, distal, occlusal and gingival) was recorded and no histological validation was carried out.

The DIAGNOdent Pen measurements were done in two different time intervals, before and after 21 days demineralization procedures. For each group, demineralization variation $(\Delta D)$ was determined as the change from baseline demineralization score to the highest demineralization, recorded after demineralization process.

\section{Statistical analysis}

Data analysis was performed by using Statistical Package for Social Sciences, (SPSS, Vers.13.0, SPSS Inc. Chicago, Illinois, USA) and Excel 2000 (Microsoft Corporation, Redmond, WA, USA). The one-way analysis of variance (ANOVA) was used to compare the variations of DIAGNOdent Pen measurements during demineralization procedures and the level of significance was set at $P<.05$. For multiple comparisons, Tukey Honestly Significant Difference (HSD) test was used. For evaluating the intra- and inter-observer

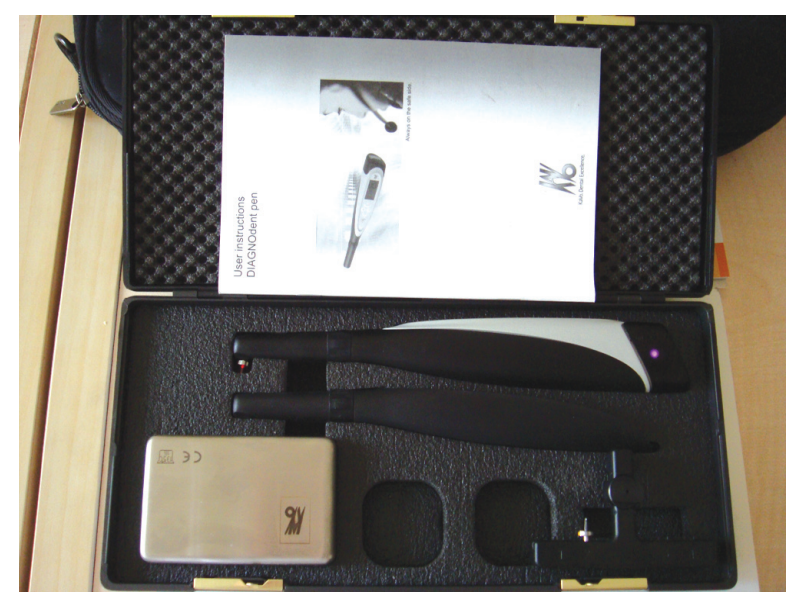

Figure 1. A set of laser fluorescence device (DIAGNOdent Pen, Kavo, Germany). agreement; the measurements were done by two investigators using the same instrument at two separate times and Cohen's Kappa scores were determined.

\section{RESULTS}

The Kappa scores for the assessment of intraand inter-observer agreement were higher than 0.75 which implies substantial agreement between the observers (Table 1).

According to ANOVA, statistically significant $\triangle D$ differences were determined among groups ( $F=6.650 ; P<.01$ ) (Table 2). The Tukey HSD test showed that the ACP-containing orthodontic composite (mean: $8.98 \pm 2.38$ ) showed the lowest $\Delta \mathrm{D}$ and the differences were found statistically significant than the control (mean: 12.15 \pm 3.83 ) $(P<.01)$. Statistically significant difference was also observed between the $\triangle \mathrm{D}$ scores of the RMGIC (mean: 9.24 \pm 2.73 ) and control groups $(P<.05)$. No significant $\triangle \mathrm{D}$ difference was found between $\mathrm{ACP}$ containing composite and RMGIC groups $(P<.05)$.

\section{DISCUSSION}

Enamel decalcification around orthodontic bands and brackets has long been a concern. ${ }^{1}$ Studies showed that orthodontic appliances increase the accumulation and adherence of plaque in mouth. ${ }^{2}$ Streptococcus mutans and Lactobacillus concentrations in the oral cavity increase in conjunction with orthodontic treatment and fixed appliances. ${ }^{3}$ These and other bacteria ferment carbohydrates to produce organic acids. These acids can, over time, lead to the dissolution

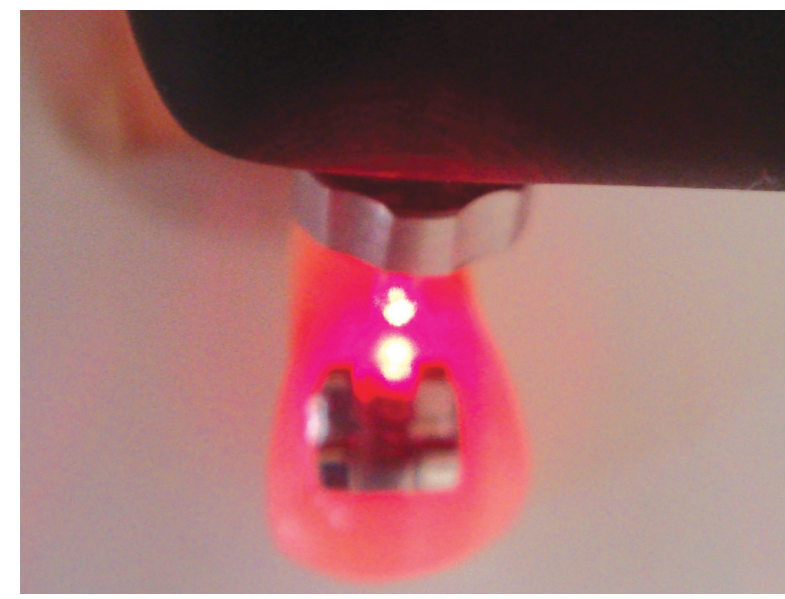

Figure 2. Measurement of the demineralization on gingival side of the bracket by DIAGNOdent Pen. 
of calcium and phosphate ions from the enamel surfaces. This process of decalcification may lead to white spot lesions and even capitation in as little as 4 weeks. ${ }^{32}$

The development and incorporation of ACP materials in dentistry is a different approach to reversing the effects of demineralization on enamel surfaces. ${ }^{29}$ The first commercially available ACP-containing materials were a sugar-free chewing gum containing casein phosphopeptideamorphous calcium phosphate (CPP-ACP) and an ACP-containing toothpaste. ${ }^{30}$ In the orthodontic literature, Sudjalim et $\mathrm{al}^{33}$ evaluated the effects of sodium fluoride ( $\mathrm{NaF}$ ) and 10\% CPP-ACP on enamel demineralization adjacent to orthodontic brackets and found that application of CPP-ACP, $\mathrm{NaF}$, or $\mathrm{CPP}-\mathrm{ACP} / \mathrm{NaF}$ can significantly prevent enamel demineralization when orthodontic composite resin is used for bonding. Recently, three investigations related to a commercially available orthodontic ACP-containing adhesive were performed and reported. ${ }^{27,29,30}$ Foster et al ${ }^{27}$ and Dunn ${ }^{29}$ compared the SBS of orthodontic brackets using ACP-containing adhesive to that of brackets bonded with a conventional orthodontic adhesive and found low but satisfactory bond strength needed to function as an orthodontic adhesive. Uysal et al ${ }^{30}$ evaluated the SBS of ACPcontaining orthodontic adhesive and conventional composite material that used as an orthodontic lingual retainer adhesive and found that ACPcontaining Aegis-Ortho adhesive resulted in a significant decrease in bond strength to the etched enamel surface. However, no studies have been performed to investigate the efficiency of ACPcontaining orthodontic composite material on enamel demineralization around the orthodontic brackets.

In a recent systematic literature review evaluating the effectiveness of fluoride in preventing white spot lesion development during orthodontic treatment, it was shown that the use

Table 1. Intra- and inter- examiner agreement in measurement of DIAGNOdent Pen values quantified by Cohen's Kappa.

\begin{tabular}{lc}
\hline Observation Type & Kappa Score (K) \\
\hline Intra-examiner agreement (examiner 1) & 0.89 \\
Intra-examiner agreement (examiner 2) & 0.85 \\
Inter-observer agreement & 0.79 \\
\hline
\end{tabular}

$\mathrm{K}<0.40$ poor agreement, $\mathrm{K}=0.41-0.60$ moderate agreement, $\mathrm{K}=0.61-0.80$ substantial agreement, $\mathrm{K}<0.75$ almost perfect agreement.

Table 2. Descriptive statistics and the comparisons of three investigated bonding materials for demineralization variations $(\Delta D)$ adjacent to orthodontic brackets.

\begin{tabular}{|c|c|c|c|c|c|c|c|c|c|c|}
\hline \multirow[b]{2}{*}{ Testing Groups } & \multirow[b]{2}{*}{$\mathrm{N}$} & \multirow[b]{2}{*}{$\Delta \mathrm{D}$} & \multirow[b]{2}{*}{ SD } & \multirow[b]{2}{*}{ SE } & \multirow[b]{2}{*}{ Min } & \multirow[b]{2}{*}{ Max } & \multirow[b]{2}{*}{ F-value } & \multirow[b]{2}{*}{$\mathrm{P}$-value } & \multicolumn{2}{|c|}{ Multiple Comparisons } \\
\hline & & & & & & & & & $\begin{array}{c}\text { ACP- } \\
\text { containing } \\
\text { composite }\end{array}$ & $\begin{array}{c}\text { Resin Modified } \\
\text { Glass lonomer } \\
\text { Cement }\end{array}$ \\
\hline $\begin{array}{l}\text { Orthodontic } \\
\text { Composite } \\
\text { (Control) }\end{array}$ & 20 & 12.15 & 3.83 & 0.86 & 6.75 & 17.50 & & & $0.005^{* *}$ & $0.010^{*}$ \\
\hline $\begin{array}{l}\text { ACP-containing } \\
\text { Orthodontic } \\
\text { Composite }\end{array}$ & 20 & 8.98 & 2.38 & 0.53 & 5.00 & 12.50 & 6.650 & $0.003^{* *}$ & & $\begin{array}{c}\text { NS } \\
0.964\end{array}$ \\
\hline $\begin{array}{l}\text { Resin Modified } \\
\text { Glass Ionomer } \\
\text { Cement }\end{array}$ & 20 & 9.24 & 2.73 & 0.61 & 6.25 & 17.00 & & & & \\
\hline
\end{tabular}

$\mathrm{N}$ indicates sample size; $\triangle \mathrm{D}$ : demineralization variation; SD: Standard deviation; SE: Standard error; ACP: amorphus calcium phosphate; RMGIC: resin modifed glass ionomer cement. 
of glass ionomer cement for bonding brackets can reduce the severity of enamel demineralization surrounding orthodontic appliances. ${ }^{34}$ The efficacy of fluoride-releasing cements in inhibiting enamel demineralization has been reported to be localized to the area around the bracket. ${ }^{35}$ The cariostatic effect is attributed to the fluoride release of both glass ionomer and RMGICs, and has been reported to occur for longer periods and with greater fluoride release levels than with fluoridecontaining composites or compomer cements. ${ }^{35}$ Thus, the second alternative for comparing the preventive effects of ACP-containing composite against demineralization around orthodontic brackets was selected as RMGIC.

The intensity of the fluorescence depends upon the wavelength of the light as well as the structure and condition of dental hard tissues. ${ }^{36,37}$ The DIAGNOdent is based on this principle. Since its first presentation, several studies have extensively investigated this laser fluorescence device for occlusal and smooth surface caries detection. ${ }^{38}$ In a recent study, a new portable laser device (DIAGNOdent Pen) which is battery powered was introduced, which allows fluorescence on the approximal surfaces of teeth to be captured. ${ }^{39}$ Many investigations were performed to evaluate the sensitivity, specificity and accuracy of this device and found good results. Novaes et $\mathrm{al}^{40}$ concluded that, both DIAGNOdent Pen and radiographic methods present similar performance in detecting the presence of demineralization or cavitations on approximal surfaces of primary molars. Laser fluorescence device is one of the most commonly used methodology in restorative dentistry, ${ }^{36-40}$ as it provides a simple, quantitative and comparable method of evaluating the performance of the various techniques. In our study all specimens were evaluated by two operators at two times to determine measurement error.

In the present study, two different commercially available bonding materials, ACP-containing composite and RMGIC, those have two different properties, compared with non-fluoridated orthodontic resin composite and showed ability to inhibit the variation of demineralized enamel lesions around bracket bases during 21 days demineralization process.

Studies of the effects of CPP-ACP have so far shown promising dose-related increases in enamel remineralization in already demineralized enamel lesions. ${ }^{41-43}$ With the limitations of any in vitro study, it can be inferred that the use of CPPACP-containing toothpaste would be beneficial in patients with enamel demineralization, because it might remineralize existing enamel lesions and also prevent the development of further white spot lesions. Kumar et al ${ }^{44}$ indicated that CPPACP containing Tooth Mousse remineralized initial enamel lesions and it showed a higher remineralizing potential when applied as a topical coating after the use of fluoridated toothpaste. In a different area Giulio et $\mathrm{al}^{45}$ determined that topical applications of CPP-ACP could be effective in promoting enamel remineralization after interdental stripping. In the present study, the ACP-containing orthodontic composite group showed the lowest $\Delta \mathrm{D}$ values and this difference was significantly lower than the control. Current preventive effects of this material were in accordance with the previous results that showed the CCP-ACP containing materials has a higher remineralizing potential than the other protective agents.

Fluoride-releasing glass ionomer cements and RMGIC have been shown to exert some cariostatic effects in both prospective and longitudinal clinical trials. ${ }^{46}$ The results of Sudjalim et al $^{33}$ indicated that, the use of RMGIC alone showing significantly reduced enamel demineralization when compared with control composite-resin samples. Present results are consistent with previous studies that RMGIC have similar demineralization values with ACP-containing composite and have preventive effects against demineralization in fixed orthodontic treatments The results indicated that fluoride release from the cements was an important factor. An in vitro study by $\mathrm{Choo}$ et a ${ }^{47}$ reported similar SBS scores and failure of brackets bonded with RMGIC and orthodontic composites. The clinician must therefore consider the benefits of fluoride release from a cement vs reduction in bond strength and the possibility of increased bond and bracket failures.

The findings of this study reinforce the need for good oral hygiene in patients whose brackets are bonded with non-fluoride-releasing composite resins. Higher scores of variations by conventional composite during demineralization process indicate white-spot lesion potential in orthodontic treatments. 


\section{CONCLUSIONS}

With the limitations of an in vitro setting, the following clinical conclusions can be drawn:

1. The ACP-containing orthodontic composite, Aegis Ortho provided the highest reductions in enamel demineralization when compared with the control.

2. The use of RMGIC for orthodontic bonding would appear to significantly prevent the development of enamel demineralization.

3. Further investigation is needed to evaluate the clinical performance and to better understand any possible adverse effects of newly developed bonding materials from its use either during or after treatment.

\section{ACKNOWLEDGEMENT}

The authors thank Guney Dental and Ertan Seçkin for their support with this project.

\section{REFERENCES}

1. Zabokova-Bilbilova E, Stafilov T, Sotirovska-Ivkovska A., Sokolovska F. Prevention of enamel demineralization during orthodontic treatment: An in vitro study using GC Tooth Mousse. Balk J Stom 2008;12:133-137.

2. Basdra EK, Huber $H$, Komposch. Fluoride released from orthodontic bonding agents alters the enamel surface and inhibits enamel demineralization in vitro. Am J Orthod Dentofac Orthop 1996;109:466-472.

3. Bloom RH, Brown LR. A study of the effects of orthodontic appliances on the oral microbial flora. Oral Surg 1964;17:658-667.

4. Mizrahi E. Enamel demineralization following orthodontic treatment. Am J Orthod 1982;82:62-67.

5. Årtun J, Brobakken BO. Prevalence of carious white spots after orthodontic treatment with multibonded appliances. Eur J Orthod 1986;8:229-234.

6. Kukleva MP, Shetkova DG, Beev VH. Comparative age study of the risk of demineralization during orthodontic treatment with brackets. Folia Med. 2002;44:56-59.

7. Gorelick L, Geiger AM, Gwinnett AJ. Incidence of white spot formation after bonding and banding. Am J Orthod 1982;81:93-98.

8. Mitchell L. Decalcification during orthodontic treatment with fixed appliances-an overview. Br JOrthod 1992;19:199205.

9. Millet DT, Nunn JH, Welbury RR, Gordon PH. Decalcification in relation to brackets bonded with glass ionomer cement or a resin adhesive. Angle Orthod 1999;69:65-70.
10. Schmit JL, Staley RN, Wefel JS, Kanellis M, Jakobsen JR, Keenan PJ. Effect of fluoride varnish on demineralization adjacent to brackets bonded with RMGI cement. Am J Orthod Dentofacial Orthop 2002;122:125-134.

11. de Bruyn H, Arends J. Fluoride varnishes: a review. J Biol Buccale 1987;15:71-82.

12. Helfenstein U, Steiner M. Fluoride varnishes (Duraphat): a meta-analysis. Community Dent Oral Epidemiol 1994;22:1-5.

13. Seppa L, Leppanen T, Hausen H. Fluoride varnish versus acidulated phosphate fluoride gel: a 3-year clinical trial. Caries Res 1995;29:327-330.

14. Arends J, Lodding A, Petersson LG. Fluoride uptake in enamel. In vitro comparison of topical agents. Caries Res 1980;14:403-413.

15. Ogaard B, Larsson E, Henriksson T, Birkhed D, Bishara SE. Effects of combined application of antimicrobial and fluoride varnishes in orthodontic patients. Am J Orthod Dentofacial Orthop 2001;120:28-35.

16. Sudjalim TR, Woods MG, Manton DJ. Prevention of white spot lesions in orthodontic practice: a contemporary review. Aust Dent J 2006;51:284-289.

17. Vorhies AB, Donly KJ, Staley RN, Wefel JS. Enamel demineralization adjacent to orthodontic brackets bonded with hybrid glass ionomer cements: an in vitro study. Am J Orthod Dentofacial Orthop 1998;114:668-674.

18. Lippitz SJ, Staley RN, Jakobsen JR. An in vitro comparative study of 24 hour and 30 day shear bond strengths of three resin-glass ionomer cements used to bond orthodontic brackets. Am J Orthod Dentofacial Orthop 1998;113:620624.

19. Farrow ML, Newman SM, Oesterle LJ, Shellhart WC. Filled and unfilled restorative materials to reduce enamel decalcification during fixed-appliance orthodontic treatment. Am J Orthod Dentofacial Orthop 2007;132:578. e1-6.

20. Hughes D, Hembree JH, Weber FN. Preparations to prevent enamel decalcification during orthodontic treatment compared. Am J Orthod 1979;76:416-420.

21. Schumacher GE, Antonucci JM, O’Donnell JNR, Skrtic D. The use of amorphous calcium phosphate composites as bioactive basing materials. Their effect on the strength of the composite/adhesive/dentin bond. J Am Dent Assoc 2007;138:1476-1484

22. Skrtic D, Antonucci JM, Eanes ED. Amorphous calcium phosphate-based bioactive polymeric composites for mineralized tissue regeneration. J Res Natl Inst Stands Technol 2003;108:167-182. 
23. Skrtic D, Antonucci JM, Eanes ED, Eidelman N. Dental composites based on hybrid and surface-modified amorphous calcium phosphates. Biomaterials 2004;25:11411150.

24. Antonucci JM, Skrtic D. Matrix resin effects on selected physicochemical properties of amorphous calcium phosphate composites. J Bioact Comput Polym 2005;20:2949.

25. Skrtic D, Hailer AW, Takagi S, Antonucci JM, Eanes ED. Quantitative assessment of the efficacy of amorphous calcium phosphate/methacrylate composites in remineralizing caries-like lesions artificially produced in bovine enamel. J Dent Res 1996;75:1679-1686.

26. Skrtic D, Antonucci JM, McDonough WG, Lui DW. Effect of chemical structure and composition of the resin phase on mechanical strength and vinyl conversion of amorphous calcium phosphate-based composites. J Biomed Mater Res 2004;68A:763-772.

27. Foster JA, Berzins DW, Bradley TG. Bond strength of a calcium phosphate-containing orthodontic adhesive. Angle Orthod 2008;78:339-344.

28. Antonucci JM, Skrtic D, Eanes ED. Remineralizing dental composites based on amorphous calcium phosphate. Polymer Prepr 1995;36:779-780.

29. Dunn WJ. Shear bond strength of an amorphous calciumphosphate- containing orthodontic resin cement. Am J Orthod Dentofacial Orthop 2007;131:243-247.

30. Uysal T, Ulker M, Akdogan G, Ramoglu SI, Yilmaz E. Bond strength of amorphous calcium phosphate-containing orthodontic composite used as a lingual retainer adhesive. Angle Orthod 2009;79:117-121.

31. Hu W, Featherstone JD. Prevention of enamel demineralization: an in-vitro study using light-cured filled sealant. Am J Orthod Dentofacial Orthop 2005;128:592-600.

32. Reich E, Lussi A, Newbrun E. Caries-risk assessment. Int Dent J 1999;49:15-26.

33. Sudjalim TR, Woods MG, Manton DJ, Reynolds EC. Prevention of demineralization around orthodontic brackets in vitro. Am J Orthod Dentofacial Orthop 2007;131:705e1-e9.

34. Benson PE, Shah AA, Millett DT, Dyer F, Parkin N, Vine RS. Fluorides, orthodontics and demineralization: a systematic review. J Orthod 2005;32:102-114.

35. Evans R, Oliver R. Orthodontic bonding using glass ionomer cement: an in vitro study. Eur J Orthod 1991;13:493-500.

36. Lussi A, Hellwig E. Performance of a new laser fluorescence device for the detection of occlusal caries in vitro. $J$ Dent 2006;34:467-471.

37. Gurbuz T, Yilmaz Y, Sengul F. Performance of laser fluorescence for residual caries detection in primary teeth. Eur J Dent 2008;2:176-184.
38. Bader JD, Shugars DA. A systematic review of the performance of a laser fluorescence device for detecting caries. J Am Dent Assoc 2004;135:1413-1426.

39. Francescut P, Zimmerli B, Lussi A. Influence of different storage methods on laser fluorescence values: a two-year study. Caries Res 2006;40:181-185.

40. Novaes TF, Matos R, Braga MM, Imparato JC, Raggio DP, Mendes FM. Performance of a Pen-Type Laser Fluorescence Device and Conventional Methods in Detecting Approximal Caries Lesions in Primary Teeth - in vivo Study. Caries Res 2009;43:36-42.

41. Rose RK. Binding characteristics of streptococcus mutans for calcium and casein phosphopeptide. Caries Res 2000;34:427-431.

42. Cai F, Shen P, Morgan MV, Reynolds EC. Remineralization of enamel subsurface lesions in situ by sugar-free lozenges containing casein phosphopeptide-amorphous calcium phosphate. Aust Dent J 2003;48:240-243.

43. Ramalingam L, Messer LB, Reynolds EC. Adding casein phosphopeptide-amorphous calcium phosphate to sports drinks to eliminate in vitro erosion. Pediatr Dent 2005;27:6167.

44. Kumar VL, Itthagarun A, King NM. The effect of casein phosphopeptide-amorphous calcium phosphate on remineralization of artificial caries-like lesions: an in vitro study. Aust Dent J 2008;53:34-40.

45. Giulio AB, Matteo Z, Serena IP, Silvia M, Luigi C. In vitro evaluation of casein phosphopeptide-amorphous calcium phosphate (CPP-ACP) effect on stripped enamel surfaces. A SEM investigation. J Dent 2009;37:228-232.

46. Gorton J, Featherstone JD. In vivo inhibition of demineralization around orthodontic brackets. Am J Orthod Dentofacial Orthop 2003;123:10-14.

47. Choo SC, Ireland AJ, Sherriff M. An in vitro investigation into the use of resin-modified glass polylalkenoate) cements as orthodontic bonding agents. Eur J Orthod 2001;23:243-252. 